National Marine

Fisheries Service

NOAA
Fishery Bulletin

2o established in 1881 \%
Spencer F. Baird

First U.S. Commissioner of Fisheries and founder of Fishery Bulletin
Abstract-The paucity of speciesspecific biological information for most exploited Indo-Pacific deepwater snappers (Lutjanidae) limits stock assessment options and management strategies. To improve stock assessments, age-based demographics were estimated for 2 deepwater snapper species, the goldeneye jobfish (Pristipomoides flavipinnis) in the Samoa Archipelago and the goldflag jobfish (P. auricilla) in the Mariana Archipelago. Each archipelago has locations where fishing had not occurred for at least 30 years, providing a rare opportunity to examine the effects of exploitation on the age and size compositions, growth, and mortality of these species. Overall, age-based data reveal a greater effect of fishing pressure than those based on size. This difference highlights concerns with size-based analyses; when species have protracted asymptotic growth trajectories, the resulting fishing impacts may not be readily apparent in size-based analyses because size and age become decoupled. This decoupling also confounds comparisons of growth among areas with different exploitation levels. Mortality estimates derived from an age-based catch curve for the unfished areas (where total mortality equals natural mortality) were comparable to those produced by using a maximumage-based natural mortality estimator. The comparison of these methods indicates that the age-based natural mortality estimator is suitable for use in deepwater snapper stock assessments when direct measures of natural mortality are unavailable.

Manuscript submitted 6 June 2019. Manuscript accepted 1 November 2019. Fish. Bull. 117:322-336 (2019). Online publication date: 22 November 2019. doi: 10.7755/FB.117.4.5

The views and opinions expressed or implied in this article are those of the author (or authors) and do not necessarily reflect the position of the National Marine Fisheries Service, NOAA.

\section{Effects of exploitation evident in age-based demography of 2 deepwater snappers, the goldeneye jobfish (Pristipomoides flavipinnis) in the Samoa Archipelago and the goldflag jobfish ( $P$. auricilla) in the Mariana Archipelago}

\author{
Joseph M. O'Malley (contact author) ${ }^{1}$ \\ Corey B. Wakefield ${ }^{2}$ \\ Zack S. Oyafuso ${ }^{3}$ \\ Ryan S. Nichols ${ }^{1}$
}

Email address for contact author: joseph.omalley@noaa.gov

${ }^{1}$ Pacific Islands Fisheries Science Center National Marine Fisheries Service, NOAA

1845 Wasp Boulevard, Building 176

Honolulu, Hawaii 96818

${ }^{2}$ Science and Research Division

Department of Primary Industries and Regional Development

39 Northside Drive

Hillarys, Western Australia 6025, Australia

${ }^{3}$ Hawaii Institute of Marine Biology

School of Ocean and Earth Science and Technology

University of Hawaii at Manoa

46-007 Lilipuna Road

Kaneohe, Hawaii 96744

${ }^{4}$ Joint Institute for Marine and Atmospheric Research University of Hawaii at Manoa

1000 Pope Road, Marine Science Building 312

Honolulu, Hawaii 96822

\author{
${ }^{5}$ Oceanic Fisheries Programme \\ Pacific Community \\ BP D5 \\ 98848 Noumea, New Caledonia \\ ${ }^{6}$ Australian Bureau of Agricultural and \\ Resource Economics and Sciences \\ Department of Agriculture \\ G.P.O. Box 858 \\ Canberra City, Australian Capital \\ Territory 2600, Australia \\ ${ }^{7}$ Fisheries Division \\ Ministry of Agriculture and Fisheries \\ P.O. Box 1874 \\ Apia, Samoa \\ ${ }^{8}$ Pacific Islands Regional Office \\ National Marine Fisheries Service, NOAA \\ 1845 Wasp Boulevard, Building 176 \\ Honolulu, Hawaii 96818
}

Many Indo-Pacific fisheries that target tropical and subtropical deepwater snappers (Lutjanidae) are considered data poor with limited fisheries information and few reliable, detailed life history studies (Williams et al., 2012, 2013; Newman et al., 2015). The available information indicates that Pristipomoides species have long life spans (>30 years), slow to moderate growth rates, and low levels of natural mortality (Newman et al. ${ }^{1}$; Newman

\footnotetext{
${ }^{1}$ Newman, S. J., D. Evans, and R. Ashworth. 2000. Assessment of the outer-shelf fishery
}

and Dunk, 2003; Andrews et al., 2012). These attributes equate to low to medium fisheries potential (Musick, 1999; Newman et al., 2016), a level of potential that makes these species inherently vulnerable to, and slow to recover from, overexploitation (Koslow et al., 2000; Clarke et al., 2003). This combination of limited fisheries data

resources off the Pilbara coast of tropical Western Australia. Final Report to the Fisheries Research and Development Corporation, Proj. No. 97/138, 78 p. Fish. West. Australia, North Beach, Australia. [Available from website.] 
and lack of life history information restricts options for quantitative stock assessment and, hence, the accurate determination of stock status needed for sustainable management.

In species of Pristipomoides, size and age can become decoupled because asymptotic size is reached at a young age relative to maximum age (Newman et al., 2016). Although fishery-dependent size information is relatively easy and cost effective to obtain compared with age data derived from collecting and analyzing aging structures, this decoupling may result in biased assessments when length data are used to define cohorts within stock assessments. As such, fishing impacts may not be readily identifiable by examining changes in fish size, highlighting the importance of age information. Hence, there is a need for accurate and timely information on age structure and agebased life history of deepwater snappers. Age-based demography furthers our understanding of deepwater snapper life history and facilitates stock assessment models and sustainable harvest strategies for these species (Brodziak et al., 2011a; Newman et al., 2016).

Species-specific life history parameters important for assessments and development of harvest strategies include growth, maturity, maximum size and age, and mortality (Quinn and Deriso, 1999; Maunder et al., 2016). Estimating natural mortality (Pauly, 1980; Then et al., 2015) is particularly important and exceedingly difficult. In datapoor situations, such as those of many deepwater snapper fisheries, total mortality is typically estimated by using catch curve analysis, and natural mortality is calculated indirectly by using empirical formulae (hereafter referred to as natural mortality estimators) derived from correlation with life history parameters or maximum age from a collection of species (Pauly, 1980; Kenchington, 2014; Then et al., 2015). Because of the lack of life history information, none of these natural mortality estimators were derived by using information specific to tropical deepwater snappers. The lack of this information is concerning because many studies show life history parameters vary among taxa (Thorson et al., 2014; Nadon and Ault, 2016) and among populations within species (Brown, 1995; Newman et al., 1996; Williams et al., 2007, 2017; Cappo et al., 2013). Further, Kenchington (2014), in a review of indirect methods, postulated that none of these natural mortality estimators are sufficiently precise to use in an analytical stock assessment.

The spatial extents of the Samoa and Mariana Archipelagoes present the opportunity to compare life history and population dynamics between exploited and unexploited populations of deepwater snappers and to test the suitability of natural mortality estimators for assessing deepwater snapper stocks. Deepwater snapper populations surround the populated islands, as well as the uninhabited islands and offshore seamounts, within the Samoa and Mariana Archipelagoes (Fig. 1).

The history of American Samoa's deepwater snapper fishery is detailed in Itano (1996) and WPRFMC ${ }^{2}$ and is

\footnotetext{
${ }^{2}$ WPRFMC (Western Pacific Regional Fishery Management Council). 2009. Fishery ecosystem plan for the American Samoa
}

briefly described here. There were 2 periods of expansion and subsequent decline in landings and effort, both due to the availability of fishing vessels (subsidized by the local government) and advances in technology. The first was in 1972, when the "dory fleet" began the commercial exploitation of shallow-water snappers and emperors (e.g., Lutjanus spp. and Lethrinus spp.) and, to a limited extent, deepwater snappers (e.g., Pristipomoides spp. and Etelis spp.) around the populated Tutuila Island and Manua Islands (Tau, Ofu, and Olosega). However, the number of dories quickly declined in 1977 to near zero.

A new period of exploitation began in 1978 with the advent of a new vessel design (called alia), which extended fishing to the offshore banks (South Bank, East Bank, Two Percent Bank, Northeast Bank, and Rose Atoll). Significant quantities of deepwater snappers, particularly Etelis coruscans and $E$. carbunculus, were landed in the early 1980 s. Etelis carbunculus is now known to be composed of 2 distinct, non-interbreeding lineages (Andrews et al., 2016). Both species occur in the Samoa Archipelago, and they were likely both captured by fishermen in the $1980 \mathrm{~s}$ but reported as one species. By 1989, fishing of deepwater snappers stopped on the offshore banks (Moffitt ${ }^{3}$ ) for reasons generally attributed to typhoons destroying vessels, fishermen leaving the deepwater snapper fishery for other fisheries, and market competition from imported fish (Levine and Allen, 2009). The results of discussions with fishermen and creel surveys $\left(\mathrm{WPacFIN}^{4,5}\right)$ indicate that little to no deepwater snapper fishing has occurred for the past 29 years at the offshore banks of American Samoa but that fishing continues around the populated islands throughout this archipelago.

The deepwater snapper fishery in the Mariana Archipelago occurs primarily in the southern portion of the archipelago from Santa Rosa Reef north to Zeelandia Bank. This area includes offshore banks (Santa Rosa Reef, Galvez Banks, Eleven-Mile Bank, and Esmerelda Bank), populated islands (Guam, Rota, Tinian, and Saipan), and unpopulated islands (Farallon de Medinilla, Anatahan, and Sarigan) (WPRFMC ${ }^{6}$; Fig. 1). The islands to the north of Zealandia Bank (Guguan, Alamagan, Pagan, Agrihan, Asuncion, Maug, and Farallon de Pajaros) have had very little historical and contemporary fishing because of the economics of traveling long distances.

Archipelago, 202 p. WPRFMC, Honolulu, HI. [Available from website.]

${ }^{3}$ Moffitt, R. B. 1989. Analysis of the depletion of bottom fishes at $2 \%$ Bank, American Samoa. NOAA, Natl. Mar. Fish. Serv., Southwest Fish. Cent., Honol. Lab. Manuscr. Rep. MRF-002-89H, 9 p.

${ }^{4}$ WPacFIN (Western Pacific Fishery Information Network). 2018. Boat-based creel survey of the Am. Samoa Dep. Mar. Wildl. Resour. [Available from website.]

5 WPacFIN (Western Pacific Fisheries Information Network). 2017. Unpubl. data. Confidential data from boat-based creel surveys. WPacFIN, Pac. Isl. Fish. Sci. Cent., Natl. Mar. Fish. Serv., NOAA. 1845 Wasp Blvd., Bldg. 176, Honolulu, HI 96818.

${ }^{6}$ WPRFMC (Western Pacific Regional Fishery Management Council). 2009. Fishery ecosystem plan for the Mariana Archipelago, 231 p. WPRFMC, Honolulu, HI. [Available from website.] 


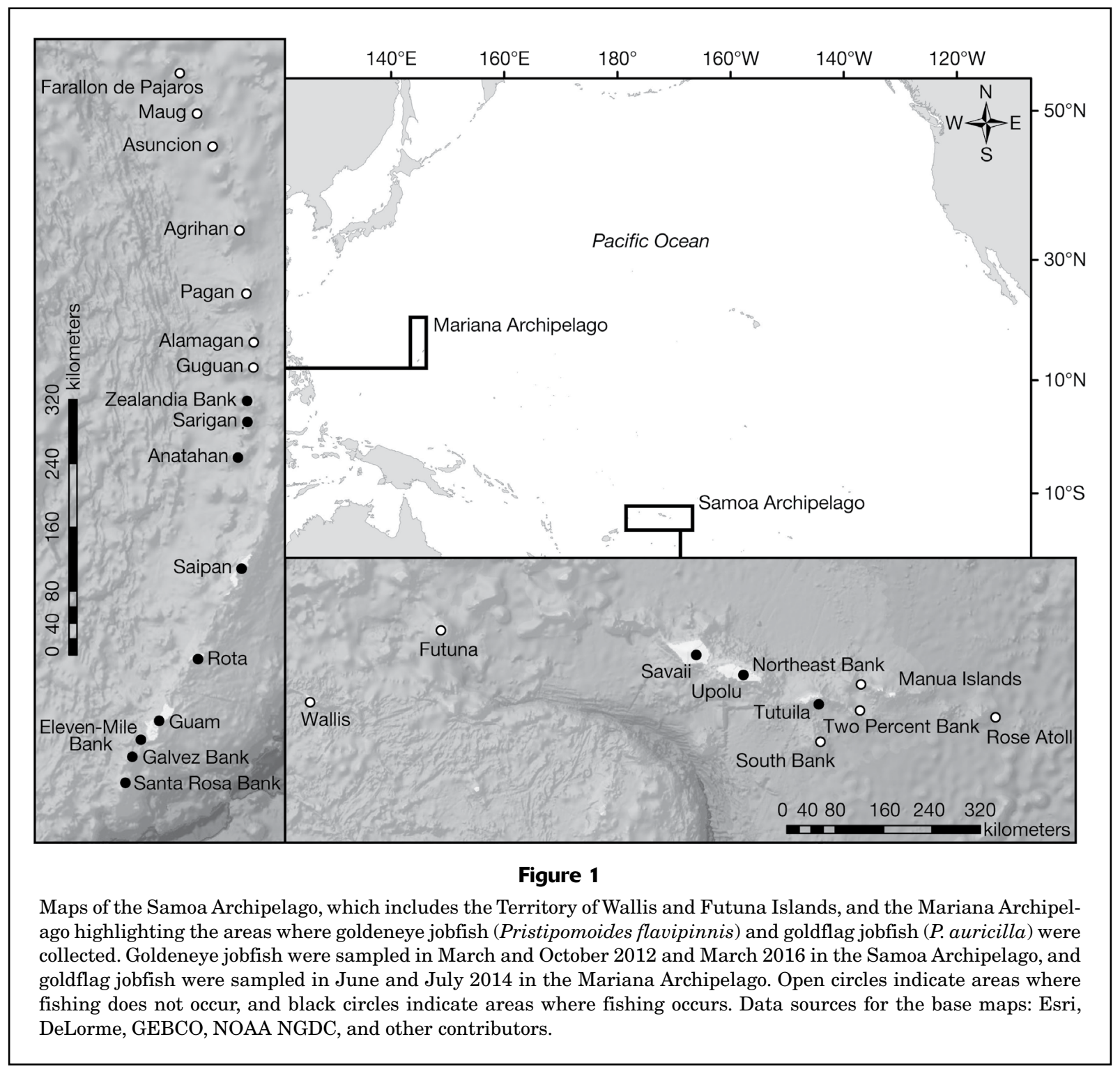

The goldeneye jobfish (Pristipomoides flavipinnis) and the goldflag jobfish (P. auricilla) are part of the deepwater demersal fishery resources of the Indo-Pacific. These snappers are widespread in the tropical and subtropical Pacific Ocean and inhabit rocky seamounts and continental slopes at depths of 90-360 m (Anderson and Allen, 2001). Both species are fished commercially and for subsistence around the populated islands and nearshore banks and seamounts throughout their range. In the U.S. territories of American Samoa, Guam, and the Commonwealth of the Northern Mariana Islands, these species are federally assessed and managed as part of a multi-species complex composed of 17 shallow-water and deepwater snappers, groupers (Epinephelinae), jacks (Carangidae), and emperors (Lethrinidae) (Yau et al., 2016). These assessments use fishery-dependent data from creel surveys in a surplus production model framework.
A recent review of this approach recommended exploring approaches based on life history parameters for the assessment process, if sufficient species-specific data are available. Reliable life history information (e.g., age, growth, and mortality) is currently unavailable for any species in this complex in the Samoa or Mariana Archipelago. Ralston and Williams (1988) estimated von Bertalanffy growth parameters and mortality rates for goldeneye jobfish and goldflag jobfish in the Mariana Archipelago by using the technique of numerical integration of daily growth increments. The resulting estimates indicate that both species had moderate growth rates and were short lived (6.7 and 4.7 years for goldeneye jobfish and goldflag jobfish, respectively). However, concerns about underestimation of fish ages produced by this method have arisen, especially for longer-lived species; therefore, the estimates are considered unreliable (Newman et al., 2016). 
The objective of this research was to compare size and age information, length at age, growth, and total and natural mortality rates for 2 deepwater snappers between areas with contrasting fishing histories. The lack of fishing effort for goldeneye jobfish at the offshore banks in American Samoa since the mid-1980s and for goldflag jobfish in the islands of the Mariana Archipelago north of Zealandia Bank allows comparison of life history parameters between exploited and unexploited areas. Moreover, the calculated total mortality rate for an unfished area is equivalent to the natural mortality rate. We compared mortality estimates produced by using an age-based catch curve analysis (for the unfished areas, total mortality equals natural mortality) to those produced by using 2 natural mortality estimators that were developed from comparative life history studies that incorporated maximum ages and growth parameters to predict natural mortality rates (Then et al., 2015). This study is the first detailed age and growth study of an eteline snapper in the Samoa or Mariana Archipelago to use the nascent methods of age-based life history parameters reported in Newman et al. (2015, 2017).

\section{Materials and methods}

\section{Sampling}

Samples of goldeneye jobfish were collected during research cruises in the Samoa Archipelago in March 2012 and March 2016 and in the Territory of the Wallis and Futuna Islands in October 2012 (Fig. 1). Fish sampled from Wallis and Futuna were added to the samples from the Samoa Archipelago offshore banks (unfished) because of their close proximity and negligible exploitation history (Adams and Chapman ${ }^{7}$ ). Goldflag jobfish were collected during research cruises in the Mariana Archipelago in June and July 2014. The Guam Biosampling Program of the NOAA Pacific Islands Fisheries Science Center also provided samples from the commercial fishery operating around Guam and nearby offshore banks.

Fish were sampled during research cruises conducted in the Samoa and Mariana Archipelagoes, by using standard vertical drop lines hauled with hydraulic or electric reels from depths between 90 and $300 \mathrm{~m}$. Research sampling in Wallis and Futuna also used vertical drop lines at similar depths between 100 and $400 \mathrm{~m}$ (Williams et al., 2017).

Each sampled fish was measured to the nearest millimeter (in fork length [FL]) and weighed to the nearest gram. Gonads were removed and preserved in $10 \%$ buffered formaldehyde. Medial transverse sections of the preserved gonads were later embedded in paraffin wax, sectioned at

\footnotetext{
${ }^{7}$ Adams, T., and L. Chapman. 2004. Overview of deepwater snapper fisheries in the SPC region. Fourth SPC heads of fisheries meeting, 30 August-4 September. Secr. Pac. Community, Info. Pap. E-IP5, 9 p.
}

$5 \mu \mathrm{m}$, mounted on slides, and stained with Mayer's haematoxylin and eosin. These histological slides were used to determine the sex of each fish. Sagittal otoliths were extracted, cleaned, and stored dry.

\section{Otolith preparation and aging criteria}

Thin otolith sections were prepared by first mounting the whole otolith to a glass slide by using thermal adhesive so that the primordium was aligned with the short edge of the slide and the sulcus acusticus was aligned perpendicular to the long edge of the slide. The otolith was ground transversely and perpendicular to the sulcus to within close proximity of the primordium by using 1600-grit diamond-coated lap on a grinding wheel. The otolith was removed from the slide edge and remounted with the previously ground section facing downward; then it was ground to a thickness of 130-150 $\mu \mathrm{m}$. The resulting thin section was rinsed in $0.5 \% \mathrm{HCl}$ for $20 \mathrm{~s}$, rinsed with fresh water, dried, and mounted to a clean slide with a glass cover slip.

Aging criteria for goldeneye jobfish and goldflag jobfish were developed by experienced readers of deepwater snapper otoliths during an international workshop on the life history of deepwater snappers and groupers (Newman et al., 2017) and refined during subsequent meetings. Thin sections were examined by using a dissecting microscope under transmitted light at 10-50x magnification. Fish ages were estimated by enumerating visible opaque zones that were assumed to be formed annually. This pattern of otolith material deposition has been validated for other deepwater snappers in the Indian Ocean (Newman and Dunk, 2003) and in the South and North Pacific Oceans (Newman et al., 2016; Wakefield et al., 2017; Williams et al., 2017). Thin otolith sections were read with no knowledge of location, date of capture, or fish size. Final decimal age estimates were determined by using the number of opaque zones, the birth date (peak spawning period: North Pacific, 1 June; South Pacific, 1 December; Moffitt, 1993), and capture date.

\section{Aging precision and bias, and age determination}

A subsample of otolith sections $(n=50)$ was read independently by 2 experienced readers (goldeneye jobfish: C. Wakefield and senior author; goldflag jobfish: R. Nichols and senior author). Aging precision (i.e., consistency in replicate otolith readings between readers) was assessed by using a modified form of the Beamish and Fournier (1981) index of average percent error (IAPE) (Wakefield et al., 2017):

$$
I A P E=\frac{1}{n} \sum_{\mathrm{j}=1}^{\mathrm{n}} \frac{\left(x_{\mathrm{ij}}-\tilde{x}_{\mathrm{j}}\right)}{\tilde{x}_{\mathrm{j}}},
$$

where $n=$ number of samples;

$x_{\mathrm{ij}}=$ the $i$ th count of the $j$ th fish; and

$\tilde{x}_{\mathrm{j}}=$ the median count for the $j$ th fish. 
Estimates of aging precision were compared with previously determined levels of acceptance of $<5.5 \%$ for IAPE (Campana, 2001; Matta and Kimura, 2012), which are applicable to deepwater snappers (Wakefield et al., 2017). Age-bias plots were examined to assess aging bias or the systematic variation in enumerated annuli counts.

The ages of all goldeneye jobfish and goldflag jobfish were estimated from the counts of opaque zones from a single age reader following the established aging criteria, with all samples read twice and at least 2 weeks between readings. Opaque zone counts for each fish were accepted if they were the same between the 2 readings, otherwise a third or, in rare cases, a fourth reading was required until a match was made with a previous count and considered the final age.

\section{Comparison of size and age distributions}

Kolmogorov-Smirnov tests were used to compare speciesspecific differences in the size and age frequency distributions between the sexes and between fished and unfished areas.

\section{Growth trajectories}

Species-specific growth of goldeneye jobfish and goldflag jobfish was described with the von Bertalanffy growth function (VBGF; von Bertalanffy, 1938) fitted to the FL at age by using nonlinear least squares regression with constant residual variance:

$$
L_{\mathrm{t}}=L_{\infty}\left(1-e^{-\mathrm{K}\left[\mathrm{t}-\mathrm{t}_{0}\right]}\right)
$$

where $L_{\mathrm{t}}=$ the predicted mean FL at age $t$ (in years);

$L_{\infty}=$ the asymptotic length (in millimeters);

$K=$ the growth coefficient (per year);

$t=$ estimated age (in years); and

$t_{0}=$ the theoretical age (in years) at which fish would have zero length.

Allowing the VBGF to estimate $t_{0}$ resulted in large negative values in some of the data sets because of the lack of smaller fish $(<200 \mathrm{~mm}$ FL). Constrained growth models $\left(t_{0}=0\right)$ provided a more realistic representation of growth for the younger age classes.

To examine the effects of sex and fishing pressure on growth, these factors were added as covariates to a constrained $\left(t_{0}=0\right)$ Kimura's (2008) extended VBGF (EVB). In this general fixed-effects nonlinear model, $L_{\infty}$ and $K$ are modeled as functions of the covariates $(\beta)$ :

$$
\left(\begin{array}{c}
L_{\infty \mathrm{i}} \\
K_{\mathrm{i}}
\end{array}\right)=\left(\begin{array}{c}
\beta_{0 \mathrm{~L}}+x_{\mathrm{i} 1} \beta_{1 \mathrm{~L}}+x_{\mathrm{i} 2} \beta_{2 \mathrm{~L}} \\
\beta_{0 \mathrm{~K}}+x_{\mathrm{i} 1} \beta_{1 \mathrm{~K}}+x_{\mathrm{i} 2} \beta_{2 \mathrm{~K}}
\end{array}\right),
$$

where $x_{\mathrm{i} 1}=$ the sex (female or male) dummy variable (either 0 or 1 ); and

$x_{\mathrm{i} 2}=$ the fishing pressure (fished versus not fished) dummy variable for the $i$ th fish.

Models with no effects, just sex, just fishing pressure, and with sex and fishing pressure were compared by using the
Akaike information criterion corrected for small sample sizes $\left(\mathrm{AIC}_{\mathrm{c}}\right.$ ) (Burnham and Anderson, 2002). Statistical analyses were conducted in the statistical software environment $\mathrm{R}$, vers. 3.5.1 ( $\mathrm{R}$ Core Team, 2018), with the nls function in the stats package.

\section{Mortality}

Estimates of natural mortality of goldeneye jobfish and goldflag jobfish were produced by applying a multinomial catch curve with logistic selectivity to the age composition of the unfished populations. This approach assumes that total mortality is equal or close to that of natural mortality. The mortality and selectivity parameters of age at $50 \%$ selectivity for the unfished population $\left(A_{50}^{\text {unf }}\right)$ and of the difference between the ages at $95 \%$ and $50 \%$ selectivity for the unfished population $\left(\Delta^{\mathrm{unf}}\right)$ were estimated from the age composition by using a multinomial negative loglikelihood ( $\left.n L L^{\mathrm{unf}}\right)$ function:

$$
n L L^{\mathrm{unf}}=-\sum_{\mathrm{a}-1}^{\mathrm{A}} C_{\mathrm{a}}^{\mathrm{unf}} \log \left(P_{\mathrm{a}}^{\mathrm{unf}}\right),
$$

where $C_{\mathrm{a}}^{\text {unf }}=$ the observed catch in numbers of age- $a$ individuals; and

$P_{\mathrm{a}}^{\mathrm{unf}}=$ the expected proportion of age- $a$ individuals in the age composition, calculated as follows:

$$
P_{\mathrm{a}}^{\mathrm{unf}}=\frac{\widehat{C}_{\mathrm{a}}^{\mathrm{unf}}}{\sum_{\mathrm{a}=1}^{\mathrm{A}} \widehat{C}_{\mathrm{a}}^{\mathrm{unf}}} .
$$

Relative catch $\left(\hat{C}_{\mathrm{a}}^{\mathrm{unf}}\right)$ of age- $a$ individuals is the product of survivorship at age $a\left(S_{\mathrm{a}}^{\text {unf }}\right)$ and gear selectivity at age $a\left(V_{\mathrm{a}}^{\mathrm{unf}}\right)$. Expected per-recruit survivorship at age in the unfished population ( $S_{\mathrm{a}}^{\mathrm{unf}}$ ) was calculated as a negative exponential function with natural mortality as the only source of mortality:

$$
\begin{aligned}
& \hat{C}_{\mathrm{a}}^{\mathrm{unf}}=S_{\mathrm{a}}^{\mathrm{unf}} V_{\mathrm{a}}^{\mathrm{unf}}, \\
& S_{\mathrm{a}}^{\mathrm{unf}}=e^{-\mathrm{M}(\mathrm{a}-1)}, \text { and } \\
& V_{\mathrm{a}}^{\mathrm{unf}}=\frac{1}{1+e^{\frac{-\log (19)\left(\mathrm{a}-\mathrm{A}_{50}^{\mathrm{unf}}\right)}{\Delta^{\mathrm{unf}}}}} .
\end{aligned}
$$

The multinomial catch curve results were compared with results from 2 natural mortality $(M)$ estimators. The first was Hoenig's (1983) updated method, which is based on maximum age (Then et al., 2015):

$$
M=4.899 t_{\max }^{-0.916}
$$

where $t_{\text {max }}=$ maximum observed age.

The second indirect method was the updated Pauly estimator, which is based on VBGF parameters (Then et al., 2015):

$$
M=4.118 K^{0.73} L_{\infty}^{-0.33},
$$

where $K=$ the growth coefficient (per year); and

$$
L_{\infty}=\text { the asymptotic length (in millimeters) estimated }
$$
by using species-specific final growth estimates. 
The estimate of natural mortality from the multinomial catch curve for the unfished populations was used as the value for natural mortality in the associated fished populations. The set of equations used to calculate total mortality in the fished areas is similar to the previous equations (with $f$ in the superscript instead of unf to indicate the fished areas), with the following modifications:

$$
\begin{aligned}
& \hat{C}_{\mathrm{a}}^{\mathrm{f}}=S_{\mathrm{a}}^{\mathrm{f}} \frac{F_{\mathrm{a}}}{Z_{\mathrm{a}}}\left(1-e^{-\mathrm{Z}_{\mathrm{a}}}\right), \\
& Z_{\mathrm{a}}=M+F_{\mathrm{a}}, \\
& F_{\mathrm{a}}=F V_{\mathrm{a}}^{\mathrm{f}}, \text { and } \\
& S_{\mathrm{a}}^{\mathrm{f}}=S_{\mathrm{a}-1}^{\mathrm{f}} e^{-Z_{\mathrm{a}}}, \\
& \widehat{C^{\mathrm{f}}}
\end{aligned}
$$

where $\widehat{C}_{\text {a }}^{\mathrm{f}}=$ expected catch in numbers of age- $a$ individuals in the fished areas;

$Z_{\text {a }}=$ age-specific total instantaneous mortality;

$F_{\text {a }}=$ fishing mortality at age;

$F=$ full fishing mortality;

$V_{\mathrm{a}}^{\mathrm{f}}=$ gear selectivity at age $a$ in the fished areas; and $S_{\mathrm{a}}^{\mathrm{f}}=$ survivorship in the fished areas.

Expected catch in numbers of age- $a$ individuals in the fished areas was calculated by using Baranov's formula: age-specific total instantaneous mortality in the fished areas is the sum of natural mortality and fishing mortality, fishing mortality at age is the product of full fishing mortality and gear selectivity at age $a$ in the fished areas, and survivorship in the fished areas is a negative exponential function of both natural mortality and fishing mortality. Selectivity was also assumed to follow a logistic function with parameters $A_{50}^{\mathrm{f}}$ and $\Delta^{\mathrm{f}}$. Values of natural mortality and total mortality, and the gear selectivity parameters in both regions, were simultaneously estimated by minimizing the sum of $n L L^{\mathrm{f}}$ and $n L L{ }^{\mathrm{unf}}$. The catch curve mortality parameters were estimated within AD Model Builder, vers. 12.0 (Fournier et al., 2012), and asymptotic standard errors were used in the calculations of the $95 \%$ confidence intervals (CIs) of the parameter estimates.

\section{Results}

\section{Aging precision, and length and age compositions}

The measures of precision between readers for opaque zone counts from thin transverse sections of otoliths were within the acceptable ranges for deepwater snappers (Wakefield et al., 2017). The between-reader IAPE was $5.2 \%$ for aging of goldeneye jobfish; $47 \%$ of the sections had exact agreement between readers, and age estimates were within 1 year for $80 \%$ of sections. The IAPE for aging of goldflag jobfish was $4.9 \%$; $32 \%$ of the sections had exact agreement between readers, and age estimates were within 1 year for $92 \%$ of sections.

The size and age of goldeneye jobfish ranged from 234 to $474 \mathrm{~mm} \mathrm{FL}$ and from 2 to 28 years old (Table 1, Fig. 2). Maximum estimated ages were similar for males (25 years) and females ( 28 years) as were the maximum sizes (males: $451 \mathrm{~mm}$ FL; females: $474 \mathrm{~mm} \mathrm{FL}$ ). The results of Kolmogorov-Smirnov tests indicate no significant differences between males and females in either size $(D=0.231$, $P=0.828)$ or age $(D=0.154, P=0.995)$ compositions. Analysis conducted with Kolmogorov-Smirnov tests revealed a significant difference in age compositions between fished and unfished areas $(D=0.5556, P<0.001)$ but not in size compositions $(D=0.385, P=0.226)$. The mean FL for combined sexes differed significantly between fished and unfished areas, with fish in unfished areas $41 \mathrm{~mm}$ larger on average than those in fished areas $\left(F_{1,371}=0.22, P=0.00\right)$. Similarly, the mean age for combined sexes differed

\section{Table 1}

Estimates of the annual growth coefficient $(K)$ and asymptotic length $\left(L_{\infty}\right)$ from the von Bertalanffy growth function, maximum ages $\left(A_{\max }\right)$, size ranges, and sample sizes $(n)$, by sex and by area (fished and unfished), for goldeneye jobfish (Pristipomoides flavipinnis) sampled from the Samoa Archipelago in 2012 and 2016 and for goldflag jobfish (P. auricilla) sampled from the Mariana Archipelago in 2014. The 95\% confidence intervals for estimates of $K$ and $L_{\infty}$ are provided in parentheses. Values of $L_{\infty}$ and in size ranges are fork lengths in millimeters. Combined=areas (fished and unfished) or sexes combined.

\begin{tabular}{llcccrr}
\hline Species & Data set & $K$ & $L_{\infty}(\mathrm{mm})$ & $A_{\max }$ & Size range $(\mathrm{mm})$ & $n$ \\
\hline P. flavipinnis & Female & $0.44(0.41-0.48)$ & $418.6(413.0-424.6)$ & 28 & $234-474$ & 179 \\
& Male & $0.51(0.46-0.56)$ & $404.1(398.4-409.8)$ & 25 & $253-451$ & 194 \\
& Fished & $0.37(0.30-0.45)$ & $429.2(402.5-463.5)$ & 10 & $234-453$ & 61 \\
& Unfished & $0.53(0.50-0.58)$ & $407.9(404.4-411.6)$ & 28 & $315-474$ & 312 \\
& Combined & $0.47(0.44-0.50)$ & $411.5(407.2-415.6)$ & 28 & $234-474$ & 373 \\
& Female & $0.56(0.51-0.62)$ & $335.2(327.8-343.1)$ & 32 & $225-400$ & 106 \\
& Male & $0.53(0.49-0.58)$ & $358.9(353.4-364.8)$ & 26 & $240-403$ & 160 \\
& Fished & $0.60(0.55-0.66)$ & $325.2(317.6-333.1)$ & 18 & $164-347$ & 135 \\
& Unfished & $0.54(0.50-0.59)$ & $358.6(353.6-363.8)$ & 32 & $225-403$ & 160 \\
& Combined & $0.51(0.48-0.54)$ & $358.5(347.5-357.5)$ & 32 & $164-403$ & 295 \\
\hline
\end{tabular}




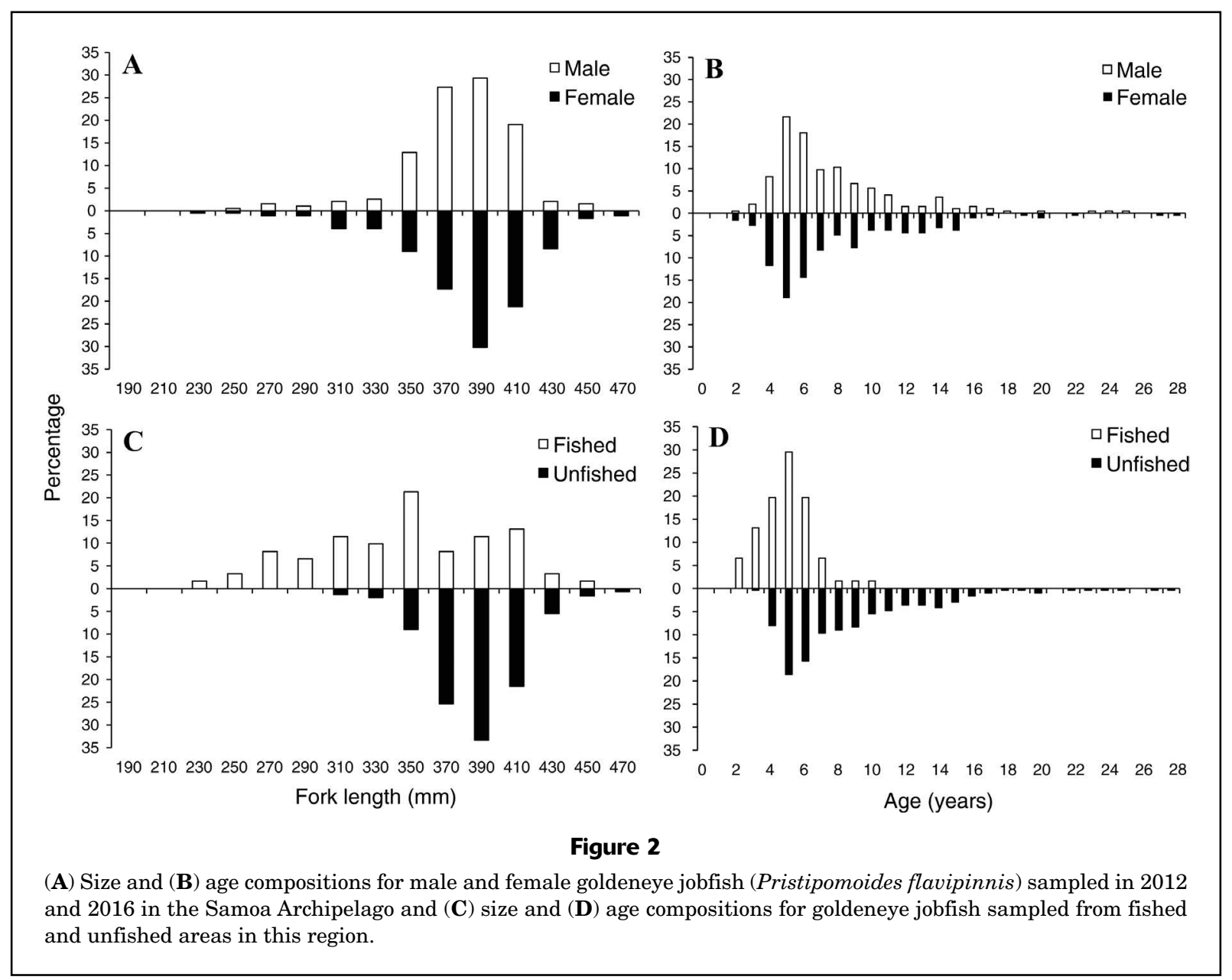

significantly between fished and unfished areas, with fish in unfished areas 3.7 years older on average than those in fished areas $\left(F_{1,371}=7.07, P<0.005\right)$. Fish from unfished areas were older and larger relative to those from fished areas. Most notably, age compositions were truncated in fished areas relative to unfished areas. The maximum age in the fished areas was 10 years compared with the maximum age of 28 years in the unfished areas. Furthermore, $30 \%$ of the individuals in the unfished areas were older than the oldest fish in the fished areas (10 years).

The size and age of goldflag jobfish ranged from 164 to $403 \mathrm{~mm}$ FL and from 2 to 32 years old (Table 1, Fig. 3). The estimated maximum age for males ( 26 years) was less than that for females (32 years), although the maximum sizes were similar (males: $403 \mathrm{~mm}$; females: $400 \mathrm{~mm}$ ). Analysis conducted with Kolmogorov-Smirnov tests revealed that the size and age compositions were significantly different between the sexes (size: $D=0.328, P<0.0001$; age: $D=0.234, P=0.001$ ). Within each sex, the results of the Kolmogorov-Smirnov tests indicate significant differences between fished and unfished areas in size compositions (male: $D=0.594, P<0.0001$; female: $D=0.506, P<0.0001$ ) and age compositions (male: $D=0.462, P<0.000$; female: $D=0.322, P=0.006$ ). Mean FLs for males and females were not significantly different between fished and unfished areas (males: $F_{1,158}=1.08, P=0.37$; females: $F_{1,104}=1.58$, $P=0.06$ ). However, mean ages for males and females were significantly older in unfished areas by 3.0 years for males and by 4.3 years for females (males: $F_{1,158}=3.57, P<0.00$; females: $F_{1,104}=6.98, P<0.00$ ). For both sexes, and similar to the results for goldeneye jobfish in the Samoa Archipelago, goldflag jobfish in the Mariana Archipelago were larger and older in the unfished areas relative to those in the fished areas, with a truncated age composition in the fished areas. The maximum ages in the fished and unfished areas were 18 years and 32 years, respectively. Of the samples from the unfished areas, $10 \%$ were older than the oldest fish from the fished areas (18 years). However, the oldest fish from the fished areas was sampled from Sarigan, the most remote island in the fished areas. The maximum age from the primary fishing grounds around Guam was 10 years.

\section{Growth}

The fit of the EVB model to the age and length data for goldeneye jobfish supported the models with factors for sex and fishing pressure (Table 2). The difference in $\mathrm{AIC}_{\mathrm{c}}$ between the best-fit model (sex and fishing pressure) and the model with the next-best fit (just fishing pressure) was 6.13. Females reached a larger $L_{\infty}$ than males and, consequently, 


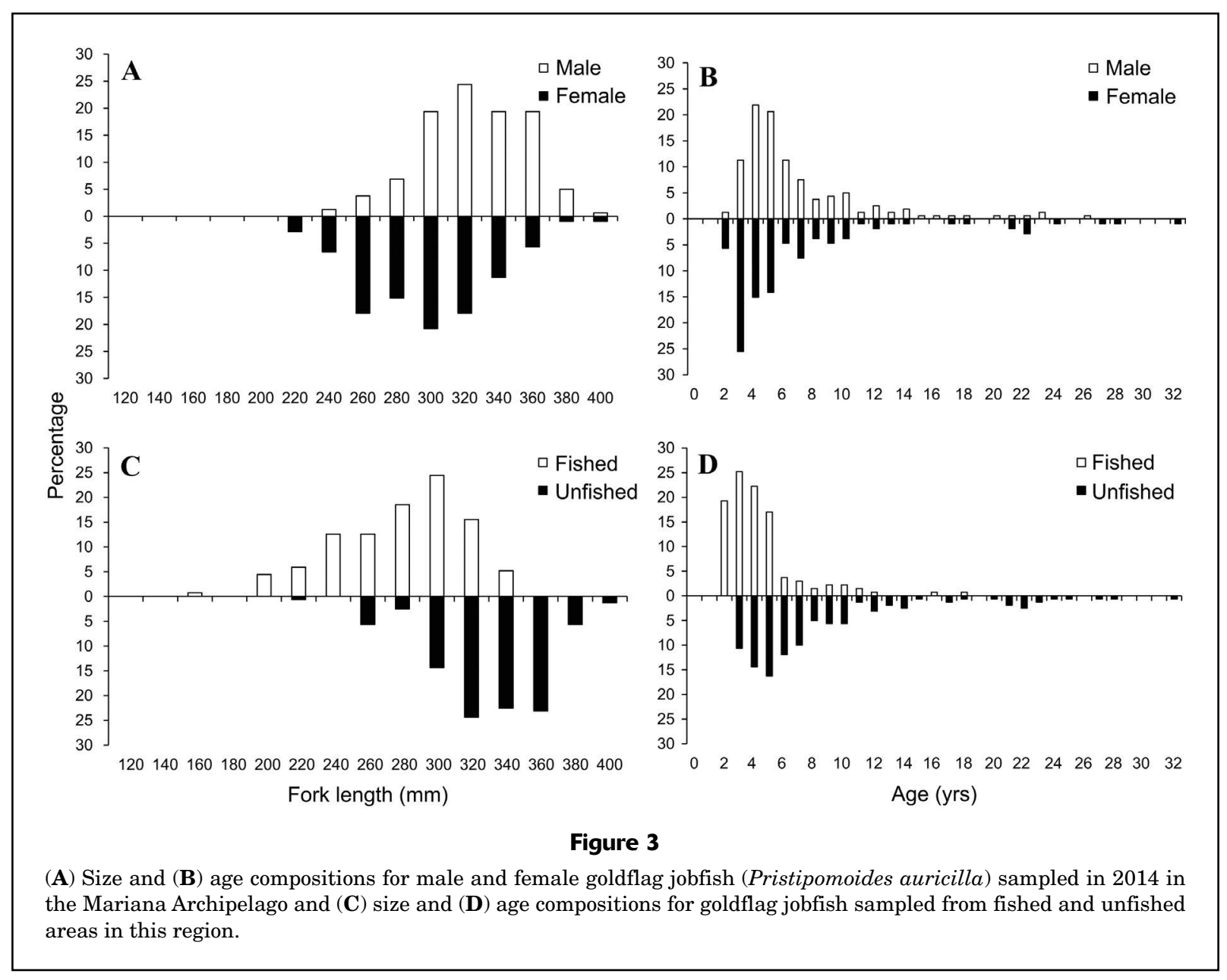

grew more slowly. However, the difference in $L_{\infty}$ was small (14.5 $\mathrm{mm} \mathrm{FL),} \mathrm{as} \mathrm{were} \mathrm{the} \mathrm{differences} \mathrm{in} K(0.07)$ and in the EVB-predicted FL at age for fish with the most common ages ( $1.13 \%$ for fish 5-6 years old). Significant but small differences were also found between the fished and unfished populations. The $L_{\infty}$ in the unfished population was $21.3 \mathrm{~mm}$ FL smaller, and fish grew slightly faster relative to the fished population. These differences in growth of goldeneye jobfish between fished and unfished areas were further confirmed by $5-6 \%$ differences in the EVBpredicted FL at age for fish with the most common ages (5-6 years). Overall, the fitted growth curve for goldeneye jobfish indicates that growth reached an asymptote between ages 6 and 9, corresponding to 20-30\% of the maximum age (Fig. 4).

The fit of the EVB model to the age and length data for goldflag jobfish supported the models with factors for sex and fishing pressure (Table 2). The difference in $\mathrm{AIC}_{\mathrm{c}}$ between the model fitted with sex and fishing pressure and the model with the next-best fit (just fishing pressure) was 46.9 . In this species, males reached a larger $L_{\infty}$ than females and, consequently, grew more slowly. However, the difference in $L_{\infty}$ was small ( $23.7 \mathrm{~mm} \mathrm{FL}$ ), as were the differences in $K(0.03)$ and in the EVB-predicted FL at age for

\section{Table 2}

Comparisons of extended von Bertalanffy growth functions fitted to length-at-age data for goldeneye jobfish (Pristipomoides flavipinnis) sampled from the Samoa Archipelago in March and October 2012 and in March 2016 and for goldflag jobfish (P. auricilla) sampled from the Mariana Archipelago in June and July 2014. Models with no covariates and with sex, fishing pressure, and sex and fishing pressure as covariates were compared by using the Akaike information criterion corrected for small sample sizes $\left(\mathrm{AIC}_{\mathrm{c}}\right)$. Also provided are the differences in $\mathrm{AIC}_{\mathrm{c}}$ between models $\left(\triangle \mathrm{AIC}_{\mathrm{c}}\right)$.

\begin{tabular}{llcrr}
\hline Species & Model & $\begin{array}{c}\text { No. of } \\
\text { parameters }\end{array}$ & $\mathrm{AIC}_{\mathrm{c}}$ & $\Delta \mathrm{AIC}_{\mathrm{c}}$ \\
\hline P. flavipinnis & Sex, fishing & 9 & 3423.3 & 0.0 \\
& Fishing & 6 & 3429.4 & 6.1 \\
& Sex & 6 & 3448.0 & 24.7 \\
& No covariates & 3 & 3456.1 & 32.8 \\
P. auricilla & Sex, fishing & 9 & 2336.7 & 0.0 \\
& Fishing & 6 & 2383.6 & 46.9 \\
& Sex & 6 & 2413.0 & 76.3 \\
& No covariates & 3 & 2453.6 & 116.9 \\
& & & & \\
\hline
\end{tabular}




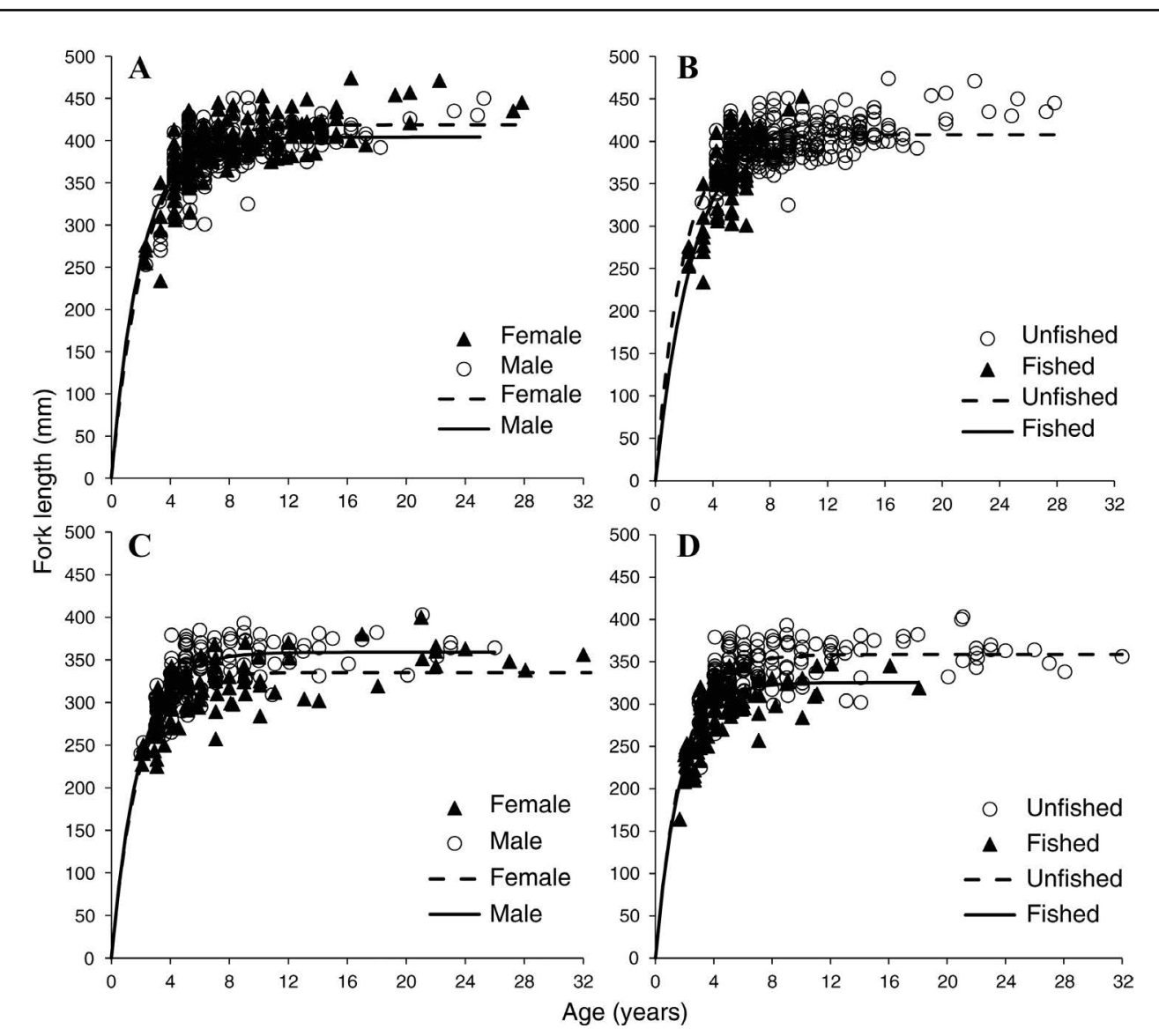

Figure 4

Lengths at age and fitted growth curves from the von Bertalanffy growth function for goldeneye jobfish (Pristipomoides flavipinnis) collected in the Samoa Archipelago in 2012 and 2016, by (A) sex (female and male) and (B) fishing pressure (fished and unfished areas), and for goldflag jobfish (P. auricilla) collected in 2014 in the Mariana Archipelago, by (C) sex and (D) fishing pressure.

fish with the most common ages (4-6\% for fish 3-6 years old). Goldflag jobfish had a growth pattern between fished and unfished areas that was the opposite of that observed for goldeneye jobfish in the Samoa Archipelago. They grew more slowly (0.06 difference in $K$ ) and reached a larger $L_{\infty}$ (difference of $33.4 \mathrm{~mm} \mathrm{FL}$ ) in the unfished areas than in the fished areas (Fig. 4, Table 1). These differences in growth of goldflag jobfish between fished and unfished areas were further confirmed by $2-10 \%$ differences in the EVB-predicted FL at age for fish with the most common ages (3-6 years). Overall, the fitted growth curve indicates that growth was similar to that of goldeneye jobfish; it reaches an asymptote between ages 6 and 9 or between $20 \%$ and $30 \%$ of the maximum age (Fig. 4 ).

\section{Mortality}

The multinomial catch curves provide a good fit to the observed age compositions for goldeneye jobfish and goldflag jobfish, as evident in the predicted proportions at age (Fig. 5). The estimated values of total mortality from the unfished areas, assumed to be an estimate of natural mortality, were 0.22 (95\% CI: 0.19-0.25) for goldeneye jobfish and 0.18 (95\% CI: 0.15-0.21) for goldflag jobfish (Table 3). Use of Hoenig's (1983) updated natural mortality estimator (Then et al., 2015) produced comparable natural mortality estimates for these same unfished areas (goldeneye jobfish: 0.23; goldflag jobfish: 0.20), whereas use of the Pauly estimator (Then et al., 2015) produced lower estimates (goldeneye jobfish: 0.17; goldflag jobfish: 0.18). Using the maximum age natural mortality estimator but substituting the maximum age from the fished areas produced greater estimates of natural mortality for goldeneye jobfish (0.59; maximum age: 10) and goldflag jobfish (0.35; maximum age:18). The values of total mortality from the fished areas, calculated by using the multinomial catch curve, are 0.89 (95\% CI: 0.36-1.42) for goldeneye jobfish and 0.42 (95\% CI: $0.34-0.50)$ for goldflag jobfish. The exploitation rates $(E)$, calculated as fishing mortality divided by total mortality, for both species differed greatly depending on whether natural mortality was determined by using the maximum age from the fished or the unfished areas. Using the natural 


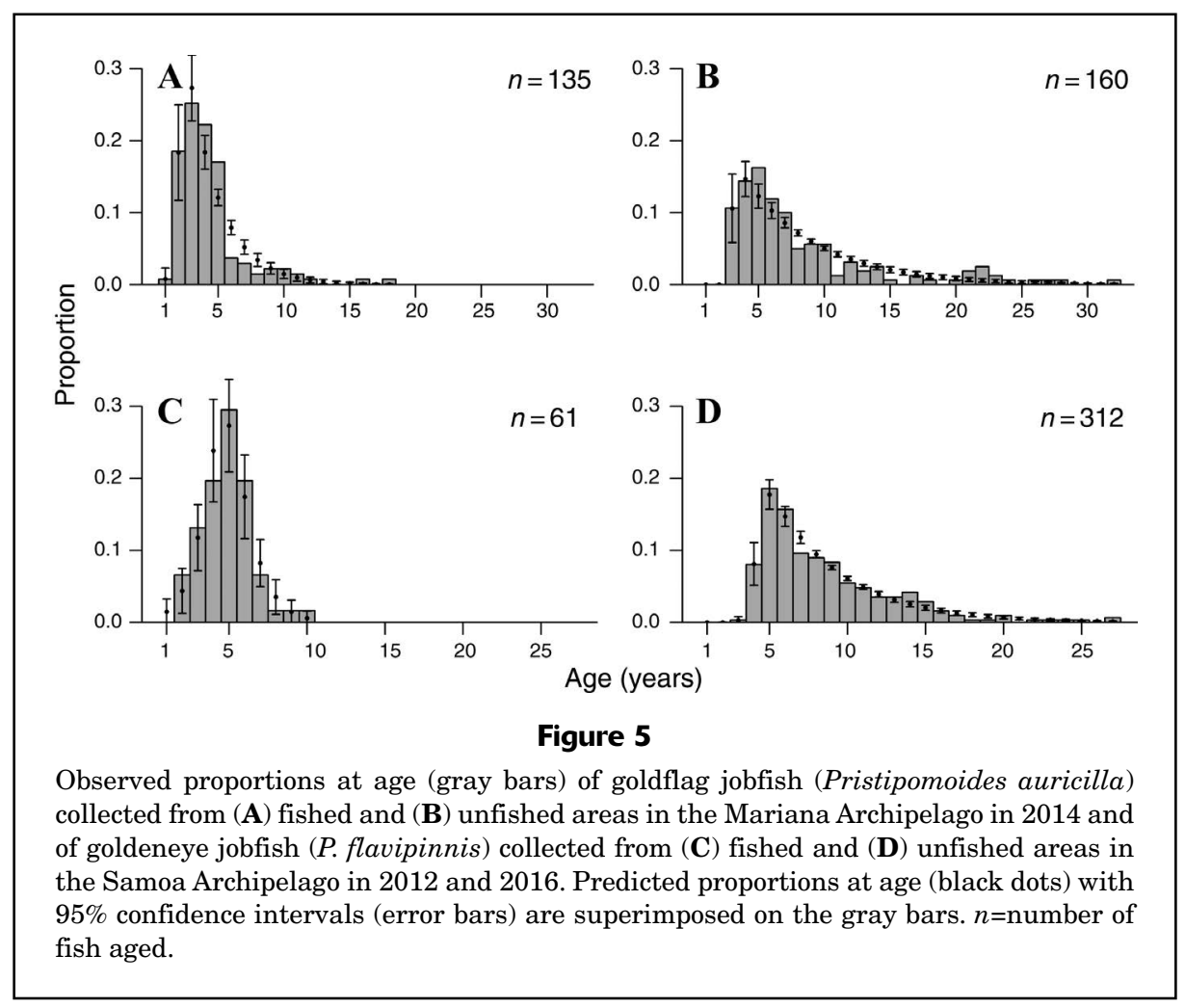

\section{Table 3}

Point estimates of natural mortality $(M)$ and selectivity in fished and unfished areas from catch curve analysis for goldeneye jobfish (Pristipomoides flavipinnis) collected from the Samoa Archipelago in 2012 and 2016 and for goldflag jobfish ( $P$. auricilla) collected from the Mariana Archipelago in 2014. Parameters include total mortality $(Z)$, age at $50 \%$ selectivity $\left(A_{50}\right)$, and the difference between ages at $95 \%$ and $50 \%$ selectivity $(\Delta)$. The $95 \%$ confidence intervals for estimates are provided in parentheses.

\begin{tabular}{lcc}
\hline Parameter & P. flavipinnis & P. auricilla \\
\hline$M$ & $0.22(0.19-0.25)$ & $0.18(0.15-0.21)$ \\
$Z$-fished areas & $0.89(0.36-1.42)$ & $0.42(0.34-0.50)$ \\
$A_{50}$-unfished areas & $4.15(3.95-4.35)$ & $2.95(2.78-3.11)$ \\
$\Delta$ - unfished areas & $0.73(0.38-1.09)$ & $0.37(0.35-0.37)$ \\
$A_{50}$-fished areas & $4.85(3.49-6.22)$ & $2.10(1.83-2.36)$ \\
$\Delta$-fished areas & $2.20(1.32-3.08)$ & $0.74(0.33-1.15)$
\end{tabular}

mortality estimates from the unfished areas and the total mortality estimate from the fished areas results in a fishing mortality of 0.66 and an $E$ of 0.74 for goldeneye jobfish, whereas using the natural mortality from the fished areas results in a fishing mortality of 0.30 and an $E$ of 0.33 . Applying the same calculations to data for goldflag jobfish results in a fishing mortality of 0.21 and an $E$ of 0.51 , whereas using the natural mortality from the fished areas results in a fishing mortality of 0.07 and an $E$ of 0.17 .

\section{Discussion}

The life histories of deepwater snappers and their sensitivity to fishing pressure are poorly understood. This study compared length- and age-based data and growth between sexes and between fished and unfished areas for the goldeneye jobfish and the goldflag jobfish, both important deepwater snapper species, in the North and South Pacific Oceans. Samples from unfished areas presented a rare opportunity to test the suitability of natural mortality estimators for deepwater snappers and offered a different perspective on the population status relative to samples collected exclusively from the fished areas.

\section{Age, growth, and mortality}

The estimates of maximum age for goldeneye jobfish (28 years) and goldflag jobfish (32 years) are much older than those originally estimated by using the technique of numerical integration of counts of daily growth increments (Ralston and Williams, 1988). These new estimates are similar to those for congeners, including 21 years for sharptooth jawfish (P. typus) from the Pilbara region of Western Australia (Newman et al. ${ }^{1}$ ), 30 years for goldbanded jobfish ( $P$. multidens) from the Kimberley region of Western Australia (Newman and Dunk, 2003), and 42 years for crimson jobfish ( $P$. filamentosus) from the Northwestern Hawaiian Islands (Andrews et al., 2012). Considering that the maximum ages reported here for the goldeneye jobfish and goldflag jobfish came from areas 
that have experienced some level of historic fishing pressure, it is possible that the true maximum ages may be greater (Newman et al. ${ }^{1}$; Newman and Dunk, 2003). The growth rates were also similar to those of other species of Pristipomoides, although the growth coefficients are slightly greater for both species. Estimates of $L_{\infty}$ and FL at age indicate that, although statistically significant, the differences between the sexes may be inconsequential because of the small differences in the estimates.

Natural mortality, generally considered one of the most difficult population parameters to estimate, is also one of the most critical and influential parameters in stock assessments (Pauly, 1980; Brodziak et al., 2011b; Thorson et al., 2017). Direct, stock-specific methods, although preferred, are typically unfeasible because of prohibitive costs and data requirements. Because of these limitations, previous research on deepwater snappers (Newman et al. ${ }^{1}, 2016$; Newman and Dunk, 2003; Burton et al., 2016; Williams et al., 2017) used indirect methods that use empirical and theoretical relationships (Beverton and Holt, 1959; Hoenig, 1983; Jensen, 1996; Then et al., 2015). These methods often suffer from low sample sizes and do not necessarily address spatial variability or taxonomic issues (Kenchington, 2014; Nadon and Ault, 2016). Estimating natural mortality by using a catch curve analysis with information from the unfished areas is considered an improvement over simply assigning a value of natural mortality (Jennings et al., 2001) or estimating it indirectly from empirical or theoretical relationships (Pauly, 1980; Hoenig, 1983; Then et al., 2015). In this study, however, the estimates of natural mortality obtained by using the multinomial catch curve analysis and by using the natural mortality estimator (maximum age method) are comparable, supporting the recommendation by Then et al. (2015) that their maximum age method provides the most reliable indirect estimates of natural mortality. The results of our research also indicate that the maximum age method is applicable for estimating natural mortality of deepwater snappers.

Using age composition data from an unfished area provides a direct estimate of natural mortality and allows the uncertainty in natural mortality to propagate to the total mortality estimate in a fished area (Maunder and Punt, 2013). The quantification of uncertainty for natural mortality also means that it can serve as a prior distribution for natural mortality in future assessments. Simulations by Punt et al. (2001) and Punt and Methot (2004) demonstrated that data collection within unfished areas (e.g., marine protected areas [MPAs]) results in improvement in the estimation of natural mortality. Garrison et al. (2011), who simulated the value of MPAs to estimate life history parameters, reported that using data collected within MPAs was an improvement to estimating natural mortality from fisheries data, although the success of estimating natural mortality was dependent on life history, movement, and model complexity.

The results of our study highlights the value of obtaining age information for longer-lived species and not relying solely on size information for parameter estimation or investigating fishing effects. In both the goldeneye jobfish and goldflag jobfish, the differences in length-based data (size composition and mean FL) between the fished and unfished areas were much smaller than the differences in age-based data (age composition and mean age). Therefore, inferences on fishery-related effects on populations may be underestimated or undetected if only length-based data are available. This is especially true for goldflag jobfish because the oldest fish (18 years) in the fished areas was sampled from Sarigan, the most remote island within the fished areas. The maximum age was 10 years around the populated island of Guam, which along with nearby seamounts and banks is the focal point of the fishery in the Mariana Archipelago.

The poor correlation between length and age occurs for other deepwater snappers that reach $L_{\infty}$ at a young age relative to their maximum age (Newman et al., 2016). The results of this study indicate that age is a more sensitive and reliable indicator of deepwater snapper exploitation relative to size, likely because of decoupling of age and length. It is critical to consider this aspect when developing monitoring programs, especially if both length and age information are available to assess stock status.

This study's findings also stress the importance of using appropriate life history values as inputs when using natural mortality estimators. The differences in maximum age between the fished and unfished areas were large (goldeneye jobfish: 10 versus 28 years; goldflag jobfish: 18 versus 32 years). Applying the Then et al. (2015) natural mortality estimator (maximum age method) to the fished areas led to a very different result, depending on which maximum age was used: estimates were close to 3 times greater for the fished area maximum age than for the unfished area maximum age. These different estimates of natural mortality contribute to very different exploitation ratios, which may result in inaccurate advice on stock status for fisheries managers. This potential for inaccuracy highlights the need for thoughtful application of natural mortality estimators and reliable estimates of maximum age when using these empirical methods.

An important assumption of the spatial comparisons and the mortality estimates is that samples from the fished and unfished areas were from the same stock, with no movement of adults between areas. This assumption is valid because preliminary research indicates that, with very few exceptions, deepwater snappers generally do not move great distances (Weng, 2013; O’Malley ${ }^{8}$ ). Also, growth of the deepwater snapper E. carbunculus varied across $20^{\circ}$ of latitude in the Pacific Ocean (Williams et al., 2017). These authors suggest that these differences in growth were driven by the metabolic theory of ecology because of large differences in temperature. Although the latitudinal gradient across the Samoa Archipelago is very

\footnotetext{
${ }^{8}$ O'Malley, J. 2015. A review of the cooperative Hawaiian bottomfish tagging program of the Pacific Islands Fisheries Science Center and the Pacific Islands Fisheries Group. NOAA, Natl. Mar. Fish. Serv., Pac. Isl. Fish. Sci. Cent. Admin. Rep. H-15-05, 36 p. [Available from website.]
} 
small $\left(<3^{\circ}\right)$ and unlikely to affect growth, the Mariana Archipelago spans $7^{\circ}$ of latitude. An experiment properly designed (with use of replicate and adjacent areas that have different fishing exposure) to evaluate the effects of fishing is required to investigate the potentially confounding environmental factors across the Mariana Archipelago.

Despite the benefits of the direct measurement of natural mortality, this estimate should still be met with some caution because of some assumptions of our modeling approach. Along with assumptions of equilibrium and of natural mortality being constant over age and time, we also assumed that the natural mortality estimated for the unfished areas can be transferred as the value of natural mortality in the fished areas. There are ecological reasons why the transferability assumption may be untenable. In the unfished areas, predation and competition may differ from that in the fished areas, resulting in a larger estimate of natural mortality (Walters et al., 1999; Macpherson et al., 2000; Martell et al., 2005). This larger value for natural mortality, in turn, may result in underestimation of fishing mortality for the fished areas if the back-calculation is made from total mortality. There will always be a risk of providing precise but inaccurate values of natural mortality from a direct method; however, treating natural mortality as a constant would provide overly confident total mortality intervals for the fished areas and bear the same risks of inaccuracy and transferability.

\section{Fishing effects, assessment, and management}

The most prominent effect from fishing on these species is the truncated age composition. This is not unexpected in commercial fisheries and is not necessarily an indication of overfishing by itself. However, there are consequences of age truncation, such as a reduction in a population's reproductive potential due to a reduced spawning stock and age-dependent maternal effects (Trippel et al., 1997; Berkeley et al., 2004; Hsieh et al., 2010). Older females spawn higher quality eggs, resulting in higher larval survival than that of their younger counterparts (Vallin and Nissling, 2000; Bobko and Berkeley, 2004; Sogard et al., 2008). They also spawn over a longer period, increasing the probability of their larvae matching optimal environmental conditions that would promote the resiliency of a population (Hsieh et al., 2008; Rodgveller et al., 2012; Rouyer et al., 2012). Loss of older individuals that have experienced several spawning events is detrimental to the reproductive potential of a population, and failure to account for these maternal effects on recruitment may introduce bias into stock assessments (Murawski et al., 2001).

Despite the lack of reliable catch information from the 1980 s, ancillary information substantiates the notion that catches of deepwater snappers from the offshore banks of American Samoa were higher prior to 1989 (Itano, 1996; WPRFMC ${ }^{2}$; Moffitt ${ }^{3}$ ). During recent research cruises, the approximate age of the oldest goldeneye jobfish caught was the same as the number of years since fishing ceased at the offshore banks and contrasts starkly with that of the oldest fish captured in the fished areas. This result indicates that, despite intensive fishing over a short period (10 years) in the 1980 s, populations of goldeneye jobfish were able to attain a broader age composition once intense fishing stopped. However, the maximum age may have yet to be realized at the offshore banks if they remain unexploited.

Why growth varied between the fished and unfished areas differently for the goldeneye jobfish and goldflag jobfish is difficult to interpret. The small sample size of goldeneye jobfish from the fished areas is a suspected issue; however, the size and age distributions do not indicate any obvious problems that would bias growth estimates. The absence of smaller and younger fish from the unfished areas could have confounded growth rate comparisons; for this reason, among others, we used the constrained growth models. Density dependence is a strong driver of growth variability (Beverton and Holt, 1957), but evolutionary effects of fishing on growth rates are also plausible (Conover and Munch, 2002; Jørgensen et al., 2007; Enberg et al., 2012). It is difficult to definitively determine or quantify the significance of either, especially the evolutionary effects of fishing on growth rates (Rose et al., 2001; Hilborn and Minte-Vera, 2008). In this case, the apparent differences in growth likely do not indicate an actual fishery-induced change in growth through density dependence or evolutionary changes but, perhaps, are a function of the fishery primarily removing the individuals that have already reached their $L_{\infty}$ but not removing significant numbers of fish below their $L_{\infty}$. This is another example of fishing having a greater effect on age than on size.

Goldeneye jobfish and goldflag jobfish are assessed and managed as part of a 17-species complex in the U.S. territories of American Samoa, Guam, and the Commonwealth of the Northern Mariana Islands. Assessing species on the level of a species complex has been criticized because the specific species that are potentially being overharvested or underutilized cannot be distinguished. The results of the assessment conducted in 2016 indicate that the species complex was not being overfished or experiencing overfishing in any of these U.S. territories (Yau et al., 2016). The mortality estimates and truncated age composition from this study indicate that the current status of goldeneye jobfish in fished areas of the Samoan Archipelago and of goldflag jobfish in fished areas of the Mariana Archipelago may not be as optimistic as the status of the species complex. It is plausible that the offshore banks act as a source for the fished areas. This is an avenue for future research. Finally, it must be noted that this study examined goldeneye jobfish throughout the entire Samoa Archipelago, including Wallis and Futuna, whereas the assessment conducted in 2016 used data from only fished areas of American Samoa.

In conclusion, goldeneye jobfish and goldflag jobfish exhibited growth and longevity similar to those of other Pristipomoides species with statistically significant but minimal sexual dimorphism in growth. Estimates of age structure and mortality for goldeneye jobfish and goldflag jobfish indicate that these populations are affected by fishing pressure around populated islands, but this impact is 
not as apparent in comparisons of size structure. Despite significant age truncation, the effects of fishing pressure on somatic growth were less clear, and the impacts on other life history traits, such as size and age at maturity, remain unknown. The results of this rare opportunity to estimate natural mortality directly indicate that the maximum age estimator of Then et al. (2015) is suitable for deepwater snappers.

\section{Acknowledgments}

The authors thank the crew of the NOAA Ship Oscar Elton Sette and participants from the Pacific Islands Fisheries Science Center, American Samoa Department of Marine and Wildlife Resources, American Samoa Office of Samoan Affairs, Independent Samoa Ministry of Agriculture and Fisheries, Independent Samoa Ministry of Natural Resources and the Environment, U.S. Embassy, University of Guam, and Commonwealth of the Northern Mariana Islands Department of Fish and Wildlife for providing ground support, permits, and their time. We thank reviewers for helpful comments. Funding was provided by AusAID, the Pacific Community, the French Pacific Fund, and the ZoNéCo.

\section{Literature cited}

Anderson, W. D., and G. R. Allen. 2001. Lutjanidae: snappers (jobfishes). In FAO species identification guide for fishery purposes. The living marine resources of the Western Central Pacific. Vol. 5. Bony fishes part 3 (Menidae to Pomacentridae) (K. E. Carpenter and V. H. Niem, eds.), p. 2840-2853. FAO, Rome.

Andrews, A. H., E. E. DeMartini, J. Brodziak, R. S. Nichols, and

R. L. Humphreys.

2012. A long-lived life history for a tropical, deepwater snapper (Pristipomoides filamentosus): bomb radiocarbon and lead-radium dating as extensions of daily increment analyses in otoliths. Can. J. Fish. Aquat. Sci. 69:1850-1869. Crossref

Andrews, K. R., A. J. Williams, I. Fernandez-Silva, S. J. Newman, J. M. Copus, C. B. Wakefield, J. E. Randall, and B. W. Bowen. 2016. Phylogeny of deepwater snappers (Genus Etelis) reveals a cryptic species pair in the Indo-Pacific and Pleistocene invasion of the Atlantic. Mol. Phylogen. Evol. 100:361-371. Crossref

Beamish, R. J., and D. A. Fournier.

1981. A method for comparing the precision of a set of age determinations. Can. J. Fish. Aquat. Sci. 38:982-983. Crossref

Berkeley, S. A., M. A. Hixon, R. J. Larson, and M. S. Love.

2004. Fisheries sustainability via protection of age structure and spatial distribution of fish populations. Fisheries 29(8):23-32. Crossref

Beverton, R. J. H., and S. J. Holt.

1957. On the dynamics of exploited fish populations, $533 \mathrm{p}$. Fish. Invest. Minist. Agric. Fish. Food, Fish. Invest. Ser. 2, vol. 19. HMSO, London.

1959. A review of the lifespans and mortality rates of fish in nature, and their relation to growth and other physiological characteristics. In Ciba Foundation colloquium on ageing. Vol. 5. The lifespan of animals (G. E. W. Wolstenholme and M. O'Conner, eds.), p. 142-180. J. and A. Churchill Ltd., London.

Bobko, S. J., and S. A. Berkeley.

2004. Maturity, ovarian cycle, fecundity, and age-specific parturition of black rockfish (Sebastes melanops). Fish. Bull. 102:418-429.

Brodziak, J., D. Courtney, L. Wagatsuma, J. O’Malley, H.-H. Lee, W. Walsh, A. Andrews, R. Humphreys, and G. DiNardo.

2011a. Stock assessment of the main Hawaiian Islands Deep7 bottomfish complex through 2010. NOAA Tech. Memo. NMFS-PIFSC-29, $176 \mathrm{p}$

Brodziak, J., J. Ianelli, K. Lorenzen, and R. D. Methot Jr. (eds.) 2011b. Estimating natural mortality in stock assessment applications. NOAA Tech. Memo. NMFS-F/SPO-119, 38 p.

Brown, J. H. 1995. Macroecology, 284 p. Univ. Chicago Press, Chicago, IL.

Burnham, K. P., and D. R. Anderson.

2002. Model selection and multimodel inference: a practical information-theoretic approach, 2nd ed., 488 p. SpringerVerlag, New York.

Burton, M. L., J. C. Potts, and D. R. Carr.

2016. Age, growth and natural mortality of blackfin snapper, Lutjanus buccanella, from the southeastern United States and U.S. Caribbean. Gulf. Caribb. Res. 27:66-73. Crossref

Campana, S. E.

2001. Accuracy, precision and quality control in age determination, including a review of the use and abuse of age validation methods. J. Fish Biol. 59:197-242. Crossref

Cappo, M., R. J. Marriott, and S. J. Newman.

2013. James's rule and causes and consequences of a latitudinal cline in the demography of John's snapper (Lutjanus johnii) in coastal waters of Australia. Fish. Bull. 111:309 324. Crossref

Clarke, M. W., C. J. Kelly, P. L. Connolly, and J. P. Molloy.

2003. A life history approach to the assessment and management of deepwater fisheries in the Northeast Atlantic. J. Northw. Atl. Fish. Sci. 31:401-411.

Conover, D. O., and S. B. Munch.

2002. Sustaining fisheries yields over evolutionary time scales. Science 297:94-96. Crossref

Enberg, K., C. Jørgensen, E. S. Dunlop, Ø. Varpe, D. S. Boukal, L. Baulier, S. Eliassen, and M. Heino.

2012. Fishing-induced evolution of growth: concepts, mechanisms and the empirical evidence. Mar. Ecol. 33:1-25. Crossref

Fournier, D. A., H. J. Skaug, J. Ancheta, J. Ianelli, A. Magnusson, M. N. Maunder, A. Nielsen, and J. Sibert.

2012. AD Model Builder: using automatic differentiation for statistical inference of highly parameterized complex nonlinear models. Optim. Methods Softw. 27:233-249. Crossref

Garrison, T. M., O. S. Hamel, and A. E. Punt.

2011. Can data collected from marine protected areas improve estimates of life-history parameters? Can. J. Fish. Aquat. Sci. 68:1761-1777. Crossref

Hilborn, R., and C. V. Minte-Vera.

2008. Fisheries-induced changes in growth rates in marine fisheries: are they significant? Bull. Mar. Sci. 83:95-105.

Hoenig, J. M.

1983. Empirical use of longevity data to estimate mortality rates. Fish. Bull. 82:898-903.

Hsieh, C.-H., S. C. Reiss, R. P. Hewitt, and G. Sugihara.

2008. Spatial analysis shows fishing enhances the climatic sensitivity of marine fishes. Can. J. Fish. Aquat. Sci 65:947-961. Crossref 
Hsieh, C.-H., A. Yamauchi, T. Nakazawa, and W. F. Wang.

2010. Fishing effects on age and spatial structures undermine population stability of fishes. Aquat. Sci. 72:165-178. Crossref

Itano, D.

1996. The development of small-scale fisheries for bottomfish in American Samoa (1961-1987). SPC Fish. Newsl. 76-77:28-44.

Jennings, S., M. J. Kaiser, and J. D. Reynolds.

2001. Marine fisheries ecology, 432 p. Blackwell Publishing, London

Jensen, A. L.

1996. Beverton and Holt life history invariants result from optimal trade-off of reproduction and survival. Can. J. Fish. Aquat. Sci. 53:820-822. Crossref

Jørgensen, C., K. Enberg, E. S. Dunlop, R. Arlinghaus, D. S. Boukal, K. Brander, B. Ernande, A. Gårdmark, F. Johnston, S. Matsumura, et al.

2007. Ecology: managing evolving fish stocks. Science 318:1247-1248. Crossref

Kenchington, T. J.

2014. Natural mortality estimators for information limited fisheries. Fish Fish. 15:53-562. Crossref

Kimura, D. K.

2008. Extending the von Bertalanffy growth model using explanatory variables. Can. J. Fish. Aquat. Sci. 65:18791891. Crossref

Koslow, J. A., G. W. Boehlert, J. D. M. Gordon, R. L. Haedrich, P.

Lorance, and N. Parin.

2000. Continental slope and deep-sea fisheries: implications for a fragile ecosystem. ICES J. Mar. Sci. 57:548-557. Crossref

Levine, A., and S. Allen.

2009. American Samoa as a fishing community. NOAA Tech. Memo. NMFS-PIFSC-19, 74 p.

Macpherson, E., A. García-Rubies, and A. Gordoa.

2000. Direct estimation of natural mortality rates for littoral marine fishes using populational data from a marine reserve. Mar. Biol. 137:1067-1076. Crossref

Martell, S. J. D., T. E. Essington, B. Lessard, J. F. Kitchell,

C. J. Walters, and C. H. Boggs.

2005. Interactions of productivity, predation risk, and fishing effort in the efficacy of marine protected areas for the central Pacific. Can. J. Fish. Aquat. Sci. 62:1320-1336. Crossref

Matta, M. E., and D. K. Kimura (eds.).

2012. Age determination manual of the Alaska Fisheries Science Center Age and Growth Program. NOAA Prof. Pap. NMFS 13, $97 \mathrm{p}$.

Maunder, M. N., and A. E. Punt.

2013. A review of integrated analysis in fisheries stock assessment. Fish. Res. 142:61-74. Crossref

Maunder, M. N., P. R. Crone, A. E. Punt, J. L. Valero, and

B. X. Semmens.

2016. Growth: theory, estimation, and application in fishery stock assessment models. Fish. Res. 180:1-3. Crossref

Moffitt, R. B.

1993. Deepwater demersal fish. In Nearshore marine resources of the South Pacific: information for fisheries (A. Wright and L. Hill, eds.), p. 73-95. Inst. Pac. Stud., Suva, Fiji.

Murawski, S. A., P. J. Rago, and E. A. Trippel.

2001. Impacts of demographic variation in spawning characteristics on reference points for fishery management. ICES J. Mar. Sci. 58:1002-1014. Crossref

Musick, J. A.

1999. Ecology and conservation of long-lived marine animals. In Life in the slow lane: ecology and conservation of long-lived marine animals (J. A. Musick, ed.), p. 1-10. Am. Fish. Soc. Symp. 23.

Nadon, M. O., and J. S. Ault.

2016. A stepwise stochastic simulation approach to estimate life history parameters for data-poor fisheries. Can. J. Fish. Aquat. Sci. 73:1874-1884. Crossref

Newman, S. J., and I. J Dunk.

2003. Age validation, growth, mortality, and additional population parameters of the goldband snapper (Pristipomoides multidens) off the Kimberley coast of northwestern Australia. Fish. Bull. 101:116-128.

Newman, S. J., D. McB. Williams, and G. R. Russ.

1996. Variability in the population structure of Lutjanus adetii (Castelnau, 1873) and L. quinquelineatus (Bloch, 1790) among reefs in the central Great Barrier Reef, Australia. Fish. Bull. 94:313-329.

Newman, S. J., C. B. Wakefield, A. J. Williams, J. M. O'Malley, S. J. Nicol, E. E. DeMartini, T. Halafihi, J. Kaltavara, R. L. Humphreys, B. M. Taylor, et al.

2015. International workshop on methodological evolution to improve estimates of life history parameters and fisheries management of data-poor deep-water snappers and groupers. Mar. Policy 60:182-185. Crossref

Newman, S. J., A. J. Williams, C. B. Wakefield, S. J. Nicol, B. M. Taylor, and J. M. O'Malley.

2016. Review of the life history characteristics, ecology and fisheries for deep-water tropical demersal fish in the Indo-Pacific region. Rev. Fish Biol. Fish. 26:537-562. Crossref

Newman, S. J., C. B. Wakefield, A. J. Williams, J. M. O'Malley, B. M. Taylor, S. J. Nicol, R. S. Nichols, S. A. Hesp, N. G. Hall, N. Hill, et al.

2017. International workshop on advancing methods to overcome challenges associated with life history and stock assessments of data-poor deep-water snappers and groupers. Mar. Policy 79:78-83. Crossref

Pauly, D.

1980. On the interrelationships between natural mortality, growth parameters, and mean environmental temperature in 175 fish stocks. ICES J. Mar. Sci. 39:175-192. Crossref

Punt, A. E., and R. D. Methot.

2004. Effects of marine protected areas on the assessment of marine fisheries. Am. Fish. Soc. Symp. 42:133-154.

Punt, A. E., A. D. M. Smith, A. J. Davidson, B. D. Mapstone, and C. R. Davies.

2001. Evaluating the scientific benefits of spatially explicit experimental manipulations of common coral trout (Plectropomus leopardus) on the Great Barrier Reef, Australia. In Spatial processes and management of marine populations. Alaska Sea Grant Rep. 01-02 (G. H. Kruse, N. Bez, A. Booth, M. W. Dorn, S. Hills, R. N. Lipcius, D. Pelletier, C. Roy, S. J. Smith, and D. Witherell, eds.), p. 67-103. Univ. Alaska Sea Grant Coll. Program, Fairbanks, AK.

Quinn, T. J., II, and R. B. Deriso.

1999. Quantitative fish dynamics, 542 p. Oxford Univ. Press, New York.

$\mathrm{R}$ Core Team.

2018. R: a language and environment for statistical computing. R Foundation for Statistical Computing, Vienna, Austria. [Available from website, accessed July 2018.

Ralston, S. V., and H. A. Williams.

1988. Depth distributions, growth, and mortality of deep slope fishes from the Mariana Archipelago. NOAA Tech. Memo. NMFS-SWFC-113, 22 p. 
Rodgveller, C. J., C. R. Lunsford, and J. T. Fujioka.

2012. Effects of maternal age and size on embryonic energy reserves, developmental timing, and fecundity in quillback rockfish (Sebastes maliger). Fish. Bull. 110:36-45.

Rose, K. A., J. H. Cowan Jr., K. O. Winemiller, R. A. Myers, and R. Hilborn.

2001. Compensatory density dependence in fish populations: importance, controversy, understanding and prognosis. Fish Fish. 2:293-327. Crossref

Rouyer, T., A. Sadykov, J. Ohlberger, and N. C. Stenseth.

2012. Does increasing mortality change the response of fish populations to environmental fluctuations? Ecol. Lett. 15:658-665. Crossref

Sogard, S. M., S. A. Berkeley, and R. Fisher.

2008. Maternal effects in rockfishes Sebastes spp.: a comparison among species. Mar. Ecol. Prog. Ser. 360:227-236. Crossref

Then, A. Y., J. M. Hoenig, N. G. Hall, and D. A. Hewitt.

2015. Evaluating the predictive performance of empirical estimators of natural mortality rate using information on over 200 fish species. ICES J. Mar. Sci. 72:82-92. Crossref

Thorson, J. T., I. G. Taylor, I. J. Stewart, and A. E. Punt.

2014. Rigorous meta-analysis of life history correlations by simultaneously analyzing multiple population dynamics models. Ecol. Appl. 24:315-326. Crossref

Thorson, J. T., S. B. Munch, J. M. Cope, and J. Gao.

2017. Predicting life history parameters for all fishes worldwide. Ecol. Appl. 27:2262-2276. Crossref

Trippel, E. A., O. S. Kjesbu, and P. Solemdal.

1997. Effects of adult age and size structure on reproductive output in marine fishes. In Early life history and recruitment in fish populations (R. C. Chambers and E. A. Trippel, eds.), p. 31-62. Chapman and Hall, London.

Vallin, L., and A. Nissling.

2000. Maternal effects on egg size and egg buoyancy of Baltic cod, Gadus morhua: implications for stock structure effects on recruitment. Fish. Res. 49:21-37. Crossref

von Bertalanffy, L.

1938. A quantitative theory of organic growth (Inquiries on growth laws. II). Hum. Biol. 10:181-213.
Wakefield, C. B., J. M. O’Malley, A. J. Williams, B. M. Taylor, R. S. Nichols, T. Halafihi, R. L. Humphreys Jr., J. Kaltavara, S. J. Nicol, and S. J. Newman.

2017. Ageing bias and precision for deep-water snappers: evaluating nascent otolith preparation methods using novel multivariate comparisons among readers and growth parameter estimates. ICES J. Mar. Sci. 74:193-203. Crossref

Walters, C., D. Pauly, and V. Christensen.

1999. Ecospace: prediction of mesoscale spatial patterns in trophic relationships of exploited ecosystems, with emphasis on the impacts of marine protected areas. Ecosystems 2:539-554. Crossref

Weng, K. C.

2013. A pilot study of deepwater fish movement with respect to marine reserves. Anim. Biotelem. 1:17. Crossref

Williams, A. J., B. D. Mapstone, and C. R. Davies.

2007. Spatial and interannual patterns in growth of an exploited coral-reef fish. J. Fish Biol. 71:970-992. Crossref

Williams, A. J., S. J. Nicol, N. Bentley, P. J. Starr, S. J. Newman, M. A. McCoy, J. Kinch, P. G. Williams, F. Magron, G. M. Pilling, et al.

2012. International workshop on developing strategies for monitoring data-limited deepwater demersal line fisheries in the Pacific Ocean. Rev. Fish Biol. Fish. 22:527-531. Crossref

Williams, A. J., K. Loeun. S. J. Nicol, P. Chavance, M. Ducrocq, S. J.

Harley, G. M. Pilling, V. Allain, C. Mellin, and C. J. A. Bradshaw. 2013. Population biology and vulnerability to fishing of deepwater Eteline snappers. J. Appl. Ichthyol. 29:395-403. Crossref

Williams, A. J., C. B. Wakefield, S. J. Newman, E. Vourey,

F. J. Abascal, T. Halafihi, J. Kaltavara, and S. J. Nicol.

2017. Oceanic, latitudinal, and sex-specific variation in demography of a tropical deepwater snapper across the Indo-Pacific region. Front. Mar. Sci. 4:382. Crossref

Yau, A., M. Nadon, B. Richards, J. Brodziak, and E. Fletcher. 2016. Stock assessment updates of the bottomfish management unit species of American Samoa, the Commonwealth of the Northern Mariana Islands, and Guam in 2015 using data through 2013. NOAA Tech. Memo. NMFS-PIFSC-51, 54 p. 